\title{
An assessment of strategic decision-making processes among small and micro enterprises in South Africa
}

\begin{tabular}{|c|c|}
\hline \multicolumn{2}{|c|}{$\begin{array}{l}\text { Authors: } \\
\text { Roger Gopaul }{ }^{1} \text { (0) } \\
\text { Renitha Rampersad }{ }^{2} \text { (] }\end{array}$} \\
\hline \multicolumn{2}{|c|}{$\begin{array}{l}\text { Affiliations: } \\
\text { 'Department of Business } \\
\text { Management, Faculty of } \\
\text { Management Sciences, } \\
\text { Durban University of } \\
\text { Technology, Durban, } \\
\text { South Africa }\end{array}$} \\
\hline \multicolumn{2}{|c|}{$\begin{array}{l}{ }^{2} \text { Department of Public } \\
\text { Relations Management, } \\
\text { Faculty of Management } \\
\text { Sciences, Durban University } \\
\text { of Technology, Durban, } \\
\text { South Africa }\end{array}$} \\
\hline \multicolumn{2}{|c|}{$\begin{array}{l}\text { Corresponding author: } \\
\text { Roger Gopaul, } \\
\text { rogergopaul@outlook.com }\end{array}$} \\
\hline \multicolumn{2}{|c|}{$\begin{array}{l}\text { Dates: } \\
\text { Received: } 28 \text { July } 2019 \\
\text { Accepted: } 03 \text { Apr. } 2020 \\
\text { Published: } 27 \text { July } 2020\end{array}$} \\
\hline \multicolumn{2}{|c|}{$\begin{array}{l}\text { How to cite this article: } \\
\text { Gopaul, R. \& Rampersad, R., } \\
2020 \text {, 'An assessment of } \\
\text { strategic decision-making } \\
\text { processes among small and } \\
\text { micro enterprises in } \\
\text { South Africa', Acta Commercii } \\
\text { 20(1), a819. https://doi.org/ } \\
\text { 10.4102/ac.v20i1.819 }\end{array}$} \\
\hline \multicolumn{2}{|c|}{$\begin{array}{l}\text { Copyright: } \\
\text { (c) 2020. The Authors. } \\
\text { Licensee: AOSIS. This } \\
\text { is licensed under the } \\
\text { Creative Commons } \\
\text { Attribution License. }\end{array}$} \\
\hline \multicolumn{2}{|l|}{ Read online: } \\
\hline 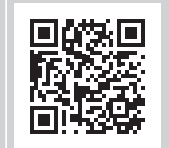 & $\begin{array}{l}\text { Scan this QR } \\
\text { code with your } \\
\text { smart phone or } \\
\text { mobile device } \\
\text { to read online. }\end{array}$ \\
\hline
\end{tabular}

Orientation: Supporting agencies and small and micro enterprises in South Africa could be endowed with an integrated model that outlines the characterisation and patterns of strategic decision-making in the small and micro service sector that will assist in understanding and improving decision-making to enhance business sustainability and competitiveness.

Research purpose: To assess the strategic decision-making process in small and micro service enterprises in South Africa.

Motivation for the study: This study was motivated by the factors affecting small and micro enterprise sustainability which included deficiencies in the strategic decision-making process.

Research design, approach and method: This study adopted a qualitative approach that captured the social realities of the decision-making process. The data collection techniques include semi-structured interviews of ten (10) respondents, four focus groups with five (5) respondents per group and five (5) businesses chosen for observation. Content analysis was used to analyse the data with the aid of NVIVO data analysis software. The data analysis software was used to organise data and identify themes.

Main findings: The process of strategic decision-making is pivoted on the intuitive decisionmaking tendencies of the business owners which reveal iterative and concurrent characteristics.

Practical/managerial implications: The effect of strategic decision-making is identified as a major challenge among small and micro enterprises leading to business failure. The implications of this research relate to identifying the most practical ways in which such decisions are formulated and devising mechanisms to enhance the decision-making process.

Contribution/value-add: The pattern of strategic decision-making exhibited a greater tendency towards intuitive decision formulation as opposed to procedural rationality and that those businesses that attempted some form of methodological environmental scan as an influencing factor in the decision-making process adopted more of an assimilated approach in the intuitiverational decision-making continuum rather than a completely procedural rational mode.

Keywords: Intuitive-rational decision-making; small medium enterprises; strategic decisionmaking.

\section{Introduction}

Small, medium and micro enterprises (SMMEs) are the backbone of the South African economy with a goal that at least $90 \%$ of new jobs will be created from small and expanding enterprises by 2030 (Groepe 2015). This aspiration is based on the reality that $90 \%$ of jobs between 1998 and 2005 were generated from SMMEs (Bushe 2019). However, SMMEs often lack the requisite resources essential in the provision and analysis of crucial environmental information fundamental to the decision-making process (Cheng, Kadir \& Bohari 2014).

Given the importance of SMMEs to the economy of South Africa, strategic decision-making in small and micro enterprises is relevant to the efficacious advancement of these businesses. Notwithstanding such significance, the definition of strategic decision-making fluctuates in practice and theory. The diverse notions of strategic decision-making are due to the consideration of the context and the various activities and cognitive approaches that constitute the process in formulating a decision (Elbanna \& Fadol 2016).

In the context of this article, the strategic decision-making process consists of diagnosing the stimulus demands that signify possible influences on the company, the consideration of alternative 
courses of action and then the selection of the most appropriate response to the situational stimuli. The article is not concerned with the actual implementation or measurement of the decision, but only on the process involved in the formulation of strategic decisions. The topic provokes a fundamental inquiry into the generation of decisions that impact the sustainability of small and micro enterprises in this specific sector. In considering the process of strategic decision-making, the study must deliberate on the contextual factors that influence such a process. This study contributed to the stock of knowledge on the process of decision-making pertaining to SMMEs in South Africa from the perspective of an intuitive-rational continuum.

\section{Literature review}

Since 1994, the structure of businesses in South Africa has evolved significantly as SMMEs are given more priority in the government's national agenda through the conveyance of policies and the establishment of distinctive agencies directed at supporting the interests of SMMEs' growth and survival. This is due to the South African government's recognition that SMMEs serve a fundamental role in the progress of South Africa's national economy and its international competitiveness (South Africa SONA 2019). The National Credit Regulator (South Africa NCR 2011) reports that the recognition of the role of SMMEs by the South African government has led to the growth and expansion of SMMEs as a key catalyst in the economic development of the country. Despite the emphasis on the development of the small business sector in South Africa, the failure rate of SMMEs is exceptionally high at an estimated $80 \%$ within the first year of existence (Bushe 2019; Masutha \& Rogerson 2014).

In South Africa, the strategic decision-making process is influenced by factors internal and external to the SMMEs which impact the firms' responses to opportunities and sustainability. Olawale and Garwe (2010) posit that environmental factors such as market variables are some of the contingency factors impacting the decision-making process. General external environmental uncertainty, consisting of the magnitude of heterogeneity and change, is a threat to business managers due to the restrictions placed in formulating strategic decisions and long-term planning to maintain relevance and equipoise with the external environment (Gupta 2013). For that reason, the variables of heterogeneity and uncertainty of the external environment in South Africa, inclusive of the market effects, are important to understand in the context of strategic formulation because they influence decisions regarding competitive advantage and performance (Sandada, Pooe \& Dhurup 2014).

Hang and Wang (2012) state that the relative inadequacy of strategic decision-making skills in response to environmental stimuli contributes to poor performance and firm demise in small enterprises. Studies conducted in South Africa suggest a relationship between poor strategic decision-making and firm performance which denotes that a formal approach to strategic decision-making is associated with improved performance (Sandada et al. 2014; Van Scheers \& Makhitha 2016). Therefore, the argument advanced by these researchers is the occurrence of a positive correlation between rational programmed strategic decisions and higher performing small businesses.

Other researchers dispute the existence of such a relationship between the formality of strategic decisions and the firm's performance (Honig \& Samuelsson 2012; Williams et al. 2018). Studies on the relationship between formal strategic decision-making and firm performance have yielded inconclusive and inconsistent results oscillating from negative relationships to positive relationships and even no relationships (Efendioglu \& Karabulut 2010). Although the debate ensues about the exact nature of the relationship between strategic decision-making and small business performance, Verreynne (2006) and Kutllovci and Shala (2013) argue that any study conducted to understand and describe the strategic decision-making process are pertinent to the profitability, survival and economic impact of the small businesses. Such studies can provide a deeper and more meaningful understanding of the nature and pattern of strategic decision-making among SMMEs in South Africa.

Although there are multiple strategic decision-making models in the academic literature, the rational model and the intuitive decision-making model are the foremost decisionmaking approaches pertaining to the study of small businesses in the context of South Africa (Van Scheers \& Makhitha 2016). One of the main debates between these two schools of thought is whether SMMEs employ a more rational approach to strategic decision-making or whether the process of strategic decision-making assumes a less programmed approach thereby adopting an intuitive orientation. Therefore, this study assesses the extent of rationality or rigidity of the process of strategic decision formulation which considers these two schools of thought.

In South Africa, SMME decision-making processes are characterised by high levels of flexibility and informality and motivated by intuitive tendencies due to unsophisticated structures, informal information sources and a lack of management skills (Ayandibu \& Houghton 2017). The lack of a programmed analytical approach to formulating decisions among these SMMEs is due to the deficiency of resources required to generate a formal mode of rationality in the decision-making process (Lekhanya 2015). Thus, SMME owners tend to approach the decision-making process in a subjective, non-sequential manner. Many of the studies conducted on the process of decision-making among SMMEs in South Africa acknowledge the dominance of an emergent and an informal approach towards the process (Van Scheers \& Makhitha 2016) but fail to describe the exact nature of this particular mode of decision formulation. Instead, these studies have resulted in multiple interventionist determinations aimed at prescribing a formal programmed approach to strategic decision-making through systematic strategic planning mechanisms in order to enhance the performance of South African SMMEs (Sandada et al. 2014). 
Different researchers have interpreted and modelled decision formulation from many different perspectives.

While the list of perspectives and literature is exhaustive and impractical to reproduce in this current study, the main thinkers on strategic decision-making are presented in order to better appreciate the distinct modes of decision formulation. From the genesis of research into strategic decision formulation, as previously indicated, there has been the debate on whether strategy adopts a rational, formal deliberate process approach as advocated by the design school of thought or whether strategy is more informal and adaptive as it evolves through a series of patterns as advocated by the emergent school of thought and the cognitive mode. Although other approaches were also proposed in an attempt to explain the process of strategic decision-making, these two modes dominate the literature.

\section{The rational decision-making mode}

The rational mode of decision-making infers that organisations approach the formulation of decisions from a formal systems perspective which constitutes a rigorous and technical procedural design to intelligence gathering, environmental analysis and response to environmental conditions (Pina 2007).

Previous research conducted on the rationality of decisionmaking, including formal planning which is indicative of rational decision-making (Zacca, Dayan \& Elbanna 2017), shows that SMMEs do not commonly engage in a formalised manner of strategic decision formulation (Cheng, Kadir \& Bohari 2014; Orser, Hogarth-Scott \& Riding 2000; Robinson \& Pearce 1984; Sandberg, Robinson \& Pearce 2001). Cheng et al. (2014) contend that there are multiple benefits to SMMEs developing a more formalised approach to information gathering and analysis in order to charter a ratified course of action. One of the main benefits of the rational approach is the equanimity of the firm's resources in the face of environmental circumstances.

Environmental information captured and analysed through systematic means equips SMMEs with a vital awareness of internal and external conditions in order to effectively manage heterogeneous uncertainties. A rational approach to small businesses strategic decisions provides a logical response to enhancing the firms' competitive position because it provides the diligently assembled information and procedural courses of action in order to achieve intended objectives (Zacca et al. 2017). Rationality allows SMMEs to identify opportunities in the market and align the business activities to appropriately respond in a deliberate manner to the environmental conditions thereby ensuring a strategic fit between the business and the situational context.

However, studies on the consequence of a formal approach to decision formulation on the performance of SMMEs remain inconclusive (Williams et al. 2018). Zacca et al. (2017) further note that a highly systematic rational approach to innovative decision formulation subdues the firm's creative progress. These studies indicate that SMMEs achieved growth and sustainability apart from the adoption of formal systems in their decision-making processes. Decisions among SMMEs tend to rely on the personal discernment and resolve flexibility of the SMME owners in their pursuit of sustainability and competitive advantage in the market.

\section{The intuitive decision-making mode}

Notwithstanding the inconclusive relationship between a formalised and rational approach to decision formulations and performance, SMMEs in South Africa tend to gravitate towards an approach that is informal rather than a formal orientation due to lack of knowledge in applying a rational and formalised system (Sandada et al. 2014). In addition, a rational approach to decision formulation may not be applicable to businesses that lack the time and resources required to gather and analyse environmental information relevant to business decisions in a timely manner. Unlike large organisations with the finance and human capital availability, SMMEs lack those essential resources or possess limited access to such resources which restricts a formal rational approach to the decision-making process (Haase \& Franco 2011).

Consequently, SMMEs rely on experience, casual information sources and intuition in the decision-making process.

As discussed earlier, SMMEs in South Africa face tremendous resource constraints which include deficient market research, inadequate business skills and lack of access to funding resulting in unsystematic decisions based on imperfect information (Ayandibu \& Houghton 2017; Gronum, Verreynne \& Kastelle 2012). Lekhanya (2015) further notes that the owners of SMMEs in South Africa seldom participate in rational planning and decision-making processes due to the lack of managerial skills combined with the inability to employ skilled personnel to provide the necessary business support. Due to such limitations, decision-making among SMMEs in South Africa is mainly the responsibility of the business owner and based on intuitive tendencies and deemed to be more informal in character (Cant, Wiid \& Kallier 2015).

Exploratory research into the process of strategic decisionmaking in small enterprises revealed that intuitive decisionmaking propensities and subjectivity were prevalent in the approach towards decision formation (Jocumsen 2004). Results further revealed that the decision-making process was iterative and consisted of 'decision initiation', 'information gathering', 'financial analysis/assessment' and 'final commitment'. In another study of the decision-making process in small enterprises, Huang (2009) notes that the process comprises 'idea initiation, information search and analysis, financial analysis, internal factor consideration, and final decision making'. Thus, the intuitive pattern of decisionmaking has been associated with small businesses where 
there are fewer formal systems and less rigid mechanisms that influence the process of decision-making (Elbanna \& Fadol 2016). These strategic decision-making models, postulated on an intuitive orientation, argue that the process generally involves the capture of information, an analysis of the information and the synthesis of options in order to achieve desired results. According to these models, each stage is characterised by informality and unstructured tendencies thereby rendering such an intuitive process of strategic decision-making as iterative and concurrent due to the need for continuous information monitoring mechanisms and revision of the process. This results in a lack of any defined conformation in the approach.

This signifies that the decision-making process does not necessarily follow a particular sequence or formality, as argued in the rational mode, but can assume flexibility and environmental adaptability as described in the intuitive decision-making approach. A singular prescribed approach to the decision-making process is impractical due to the contextual changes and complexities that remain ill defined. Any attempt at effecting relevant intervention to improve the process of strategic decision-making among SMMEs in South Africa necessitates an assessment of their current practices pertaining to decision formulation.

\section{Methodology}

The study employed a qualitative methodology consistent with the exploratory character of the research and the requirement for content rich data. The seminal work of Mintzberg, Raisinghani and Theoret (1976) effectively used a qualitative methodology in examining strategic decisionmaking in order to better understand the nature of the process. A qualitative methodology was also used in contemporary studies aimed at acquiring an in-depth understanding of the strategic decision-making process of small and micro firms (Liberman-Yaconi, Hooper \& Hutchings 2010).

For this study, the researchers selected the small and micro services sector because few studies have focused on decisionmaking and strategy formulation in this particular business segment in South Africa. The researchers used the database of the Riversand Incubator Hub, the Commonwealth Business Women Forum, the Women Entrepreneurs 300 and the Gauteng Enterprise Propeller in order to obtain a list of small and micro enterprises within the services sector operating in Gauteng, South Africa. These enterprises were registered companies and satisfied the criteria of small and micro enterprises which have fewer than 50 employees, an annual turnover of less than R19 million and total gross assets of less than R3 million.

Another essential criterion is that each person identified as part of the sample must own and manage the business. A purposive sampling technique was used to select the participants based on these criteria (Etikan, Musa \& Alkassim 2016).
Data collection techniques included semi-structured interviews, focus groups and observations. Ten respondents participated in the semi-structured interviews, four focus groups were held consisting of five respondents per group and five businesses were selected for observation. The sample sizes for each respective data collection technique was deemed appropriate for a qualitative study because it afforded the prospect of extracting rich data with a view to data saturation (Asiamah, Mensah \& Oteng-Abayie 2017; Marshall et al. 2013).

Data were captured electronically and then transcribed into a Word document. NVIVO was used to generate documents from the data gathered, edit the data appropriately, explore the data content, search for associations and data relationships, and create nodes of the discovered concepts within the data. The data were assessed using content analysis which allowed the researcher to gather novel perspectives on emerging and noteworthy themes and subthemes (Liberman-Yaconi et al. 2010). The researcher revisited each theme which was then arranged into an intelligible and internally harmonious account of an overarching impression. This phase required the researcher to consider each commonality in relation to the others so that the overall scope of the data findings and its meaning can be accurately understood. The patterns that emerged from the content analysis, associated with the relevant literature, provided the foundation for the development of a strategic decisionmaking framework reflective of small and micro enterprises in South Africa.

\section{Analysis}

The results of the data collected from the semi-structured interviews and focus groups indicated patterns of intuitive orientation in the decision-making process as demonstrated in the selected evidence provided in Table 1 and Table 2

Table 1 and Table 2 provide a sample of responses gathered from the semi-structured interview stage and focus groups of the data collection initiative. The first aspect of the strategic decision-making process relates to the decision trigger which is the situational factors or events that initiated the decision. The respondents in both the semi-structured interviews and focus groups confirmed that most decisions were triggered by market-related sources that were informal or casual in nature. However, those respondents indicated the decision-making process was more reactive to the situational context rather than proactive. The reactive nature of the respondents was frequently conveyed as 'following the money trend' or 'influenced by what bloggers are doing' thereby indicating that the situational factors influenced the decision-making process. A similar occurrence was noted in observation session 4 where the information emanated from social media.

As such, decisions were not taken on the basis of premeditated considerations aimed at impacting the market context. The data also reveal that such initiation of the decisionmaking process is activated 'without planning' because 
TABLE 1: Semi-structured interview samples of the strategic decision-making process.

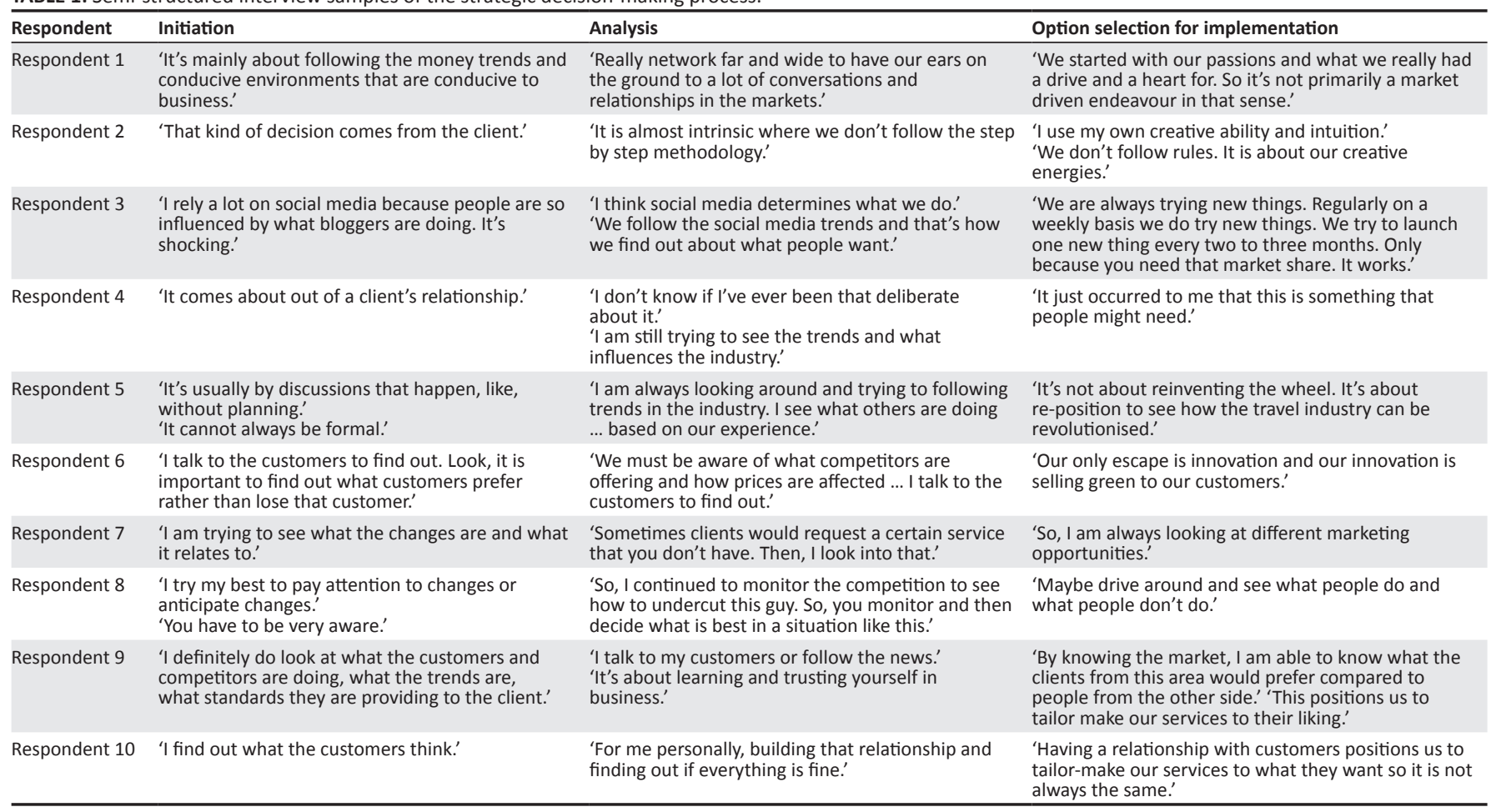

TABLE 2: Focus group samples of the strategic decision-making process in the context of the market.

\section{Process}

Participants admitted that not much deliberate thought is put into devising marketing plans. Some even said that no marketing was done because of a lack of skills. Some owners determine the conditions of the market based on trends in sales and customer buying patterns. All owners admitted the need to know the competitors in order to compete in terms of prices and quality. One business owner said that these sources are not formal but based on everyday observation and just simple understanding of the market. Other owners adjusted prices based on competitors' prices and feedback from customers. Some owners said that their decisions are based on faith and trusting in a higher being.

A few participants said that they don't advertise their businesses but depend on word of mouth in order to grow sales and determine what the market wants. Focus on giving each client special attention was a popular marketing tool used by the owners. One owner admitted to visiting competitors businesses to determine what services they offer in order to improve their own services.

The majority of businesses admitted to the lack of a formal method of gathering information about and analysing competitors. Casually scanning social media was a popular method of knowing what the competitors are doing and what customers want.

The business owners depend on customer feedback through close customer relations as the most important factor in getting information on the market and competitors' offerings. This information is used to decide what services to offer and prices to set. The owners emphasised the value of experience in dealing with customers and knowing what to expect.

'it cannot always be formal' thereby indicating an informal and unintentional dimension to decision formulation among these business owners.

The second aspect of the decision-making process relates to the interpretation of information emanating from the market. Despite the reactive tendencies of the respondents towards market conditions that triggered the decision-making process, the significance of an analysis of the market environment was apparent in the expressions of the participants. According to Cowling et al. (2015), the changes in the environment of small firms have a direct impact on their sustainability due to their level of vulnerability thereby requiring a thorough analysis of such contingencies by the business owners. The semi-structured interview respondents noted the importance of being 'very aware' of market conditions in order to recognise 'what it relates to'. Focus group 1 also confirmed the criticality of understanding the market factors in order to effectively compete.

The sources of information, upon which the analysis is based were derived passively using unstructured approaches in the data gathering method. Five of the semi-structured interview respondents identified social relationships with their customers as essential sources of information used in analysing and interpreting the conditions of the market. Such relationships involved inertly assessing what the customers are doing or simply 'talk[ing] to the customers to find out' or casually 'monitor[ing] the competitor' in order to determine the best strategy.

Semi-structured interview respondent 9 relied on gaining information from the 'news' in order to determine the conditions of the business environment. Therefore, the gathering of data was not conducted in a programmed manner nor was the information subjected to a formal systematic analysis. A similar reflection was noted in observation session 2 in which case the analysis of a situational context was conducted on the basis of feelings and experiences. In other cases, the focus group respondents expressed dependence on feelings, personal thoughts and past experiences in the analysis of market information. This is consistent with the findings of Malewska (2015) 
who notes that intuitive decision-making is an approach that utilises experiences, one's attitude to life and personal aptitudes. Most of the focus group respondents indicated that such were not based on complete market information but rather based on intuitive tendencies and experience.

Most of the semi-structured interview respondents profoundly stated that market assessment did not conform to a systematic analysis but was rather significantly influenced by the business owners' personal experiences and in a non-sequential manner. Semi-structured interview respondent 2 was explicit in the indication that they 'don't follow a step-by-step methodology' whereas another respondent based their analysis by having 'ears on the ground'. Semi-structured interview respondent 5 based their interpretation of the situational context on past experiences. It was therefore common among the semistructured interview respondents to rely on 'trusting yourself in business'. This is further evidenced by the regular use of phrases such as 'for me personally', 'always looking around' and 'still trying to see the trends' and deciding 'what is best in a situation like this'. It was also noted by the focus group participants that trends remained a key factor in the generation of possible information in an attempt to influence the product and service offerings as well as looking at competitors by monitoring their market offerings. As such, the sources of information and interpretation techniques used in the decisionmaking process were informal and generally depended on social relationships and the personal skills of the owner in gathering market intelligence. As in the case of observation session 2, staff were reminded of the importance of engaging with and listening to customers in order to identify opportunities and understand trends in a fast-changing environment. This suggests that the main sources of information were informal and interpreted casually based on social relationships as opposed to the use of formal research mechanisms as the means of market data capture. Small, medium and micro enterprises face market and economic volatility and uncertainties due to the rapidity of changes which are usually beyond the control of the business owners. Studies reveal that high levels of uncertainty, ominous environmental factors and the lack of external control reduce the extent of rationality in the decision-making process (Eisenhardt \& Zbaracki 1992; Elbanna \& Fadol 2016).

It was evident from the data narratives that the process of gathering and interpreting environmental market information from the varying sources was also iterative. For example, semi-structured interview respondent 7 was 'always looking at different marketing opportunities' which involved a recurrent monitoring of the market in order to inform their strategic decisions. This was also inferred by the respondents in focus group 4 who mentioned that market information gathering is not a preconceived sequential rationale; they stated that the information source for the decision-making process was based on continuous discussions with clients that informed the options generated. Focus group 2 respondents based their market interpretation and option generation on continuously monitoring competitors' businesses thereby indicating a fluid and cyclical approach to decision formulation. The fashion in which the market environment is monitored and construed is non-sequential and usually involves an iterative style in its approach towards information gathering and interpretation which confirms the findings of Malewska (2015) that strategic intuitive decisionmaking is not an irrational approach but one that leans more toward flexibility and situational adaptability.

The third aspect of the decision-making process relates to the generation of options for implementation. The strategic options of niche marketing, product re-positioning, product improvement, product development and differentiated features were some of the key differentiated factors discussed by the respondents. Gao and Hafsi (2018) recommend that firms seeking to gain a competitive advantage should explore various sources of differentiation which includes features of a product, channels of distribution and customisation of the product to meet the needs of the user. However, the concept of generating options in the decision-making process was also informal, amorphous and loosely iterative in development. Focus group 3 confirms such an approach because there is the need to always monitor the market and keep abreast of the latest information because they have to adapt to the changes. Semi-structured interview respondent 2 admitted that a sequential rational approach is extraneous to their notion of option development as the preferred method for decision-making was more iterative rather than step by step. The development of options was also reactive as opposed to a deliberate purposefully measured choice by which to guide the firm. This was evident as most respondents mentioned that their offerings are based on the request of clients as opposed to objective market analysis.

Semi-structured interview respondent 2 acknowledged that option generation encompasses 'innovation and creativity' in formulating new service offerings for client consumption. An intuitive approach to the generation of options was also noted in observation session 2 during a staff meeting. During the observation, the business owner urged staff to use their 'creative faculties' in order to suggest new ideas and opportunities.

Such option generating creativity in new service formulation was also adopted by a focus group 2 participant who expressed the need to 'offer things they don' $t$ '. Semistructured interview respondent 5 stated that the process for option formation did not seek innovation as a possibility but rather relied on repositioning the same product in the same market. On the other hand, semi-structured interview respondent 3 was willing to incrementally adjust with the market changes.

For example, semi-structured interview respondent 10 explored decision options such as new service development based on discussions with clients. Besides market penetration and service development options, other forms of strategic options were also explored. Focus group 2 based their 
strategic option on what competitors are doing resulting in the development of distinguishable features by offering something different. During one observation session, staff were encouraged to constantly seek 'new avenues' to 'offer services that exceed' clients' expectations.

The data narratives in this particular context imply the generation of options followed conventional models of identifying and exploiting differentiated strategies in the services offered in order to gain competitive advantage. However, the process involved in developing these options was less defined and reactive. This implies that the respondents adopted passive techniques towards decisionmaking that characterised the market environmental analysis and the preferred source of market information.

Overall, the data narratives indicate that the strategic decision-making process generally assumed three stages which are information gathering, information interpretation and option generation. The focus group participants and the semi-structured interview participants shared a similar approach toward the gathering of data, sourcing information from informal or casual sources. The observation sessions also yielded a consistent approach whereby the main sources of information were word of mouth and social relations. The manner of information interpretation from the data sources among the interview participants was highly informal and unstructured. This was also reflected among the focus group participants where the analysis of environmental information was associated with personal feelings and experiences as was the case among the companies observed. The generation of options for eventual implementation did not differ in formality from the previous stages of information gathering and interpretation. The three data-gathering techniques displayed parallel notions of flexibility and concurrency in formulating options for implementation. The intuitive orientation of the strategic decision-making process outlined herein is coherent with the literature in terms of the process of strategic decision formulation among the small business sector (Cant \& Wiid 2013; Masutha \& Rogerson 2014). Further supporting the findings of this study, the literature denotes that the pattern of strategic decision-making predominant in small and micro enterprises supports the notions of cyclical, flexible, emergent, experiential and unsystematic characteristics consistent with an intuitive decision-making mode (Jocumsen 2004; Mitchelmore \& Rowley 2013).

A consequence of environmental dynamism and concentration of responsibility on the owners of small and micro enterprises in South Africa is that there is an orientation towards making decisions based on those significant facets of intuitive orientation which are the owners' reliance on personal judgement, past experiences and personal feelings. Such business owners therefore benefit from substantial autonomy in utilising flexibility, discernment and experience in generating important decisions without the constraints of rigid formal procedures.

\section{Recommendation}

The study indicated that the strategic decision-making found in the small and micro enterprises had few phases and less complexity with regard to the decision formation procedures, which is dissimilar to the sequential rational approaches featured in much of the literature on the decision-making process. The decision-making process possessed an intuitive orientation which determined the cyclical and flexible character of the process as opposed to procedural and distinct phases. As such, it was important to illustrate the process of strategic decision-making from the perspective of small and micro enterprises thereby adding a model to the literature stock that is reflective of the small business sector in South Africa.

The integrated theoretical model of the strategic decisionmaking process, as proposed in Figure 1, may be used by both business practitioners and policymakers. The researcher proposes the utilisation of the integrated strategic decisionmaking model as a way of understanding the plethora of environmental influences and triggers to the decision-making process idiosyncratic to the small business sector in South Africa. The user can also gain an understanding of the character and relationships of the various phases involved in decision formation.

The strategic decision-making process model illustrates the contextual variables that influence the decision formation within small and micro enterprises in South Africa. The external forces depicted in the model are the peripheral environmental factors that affect small and micro businesses within the services industry in South Africa. From the business owner's perspective, the model can be used to provoke a more meaningful analysis of the external forces that potentially impact the small business services sector.

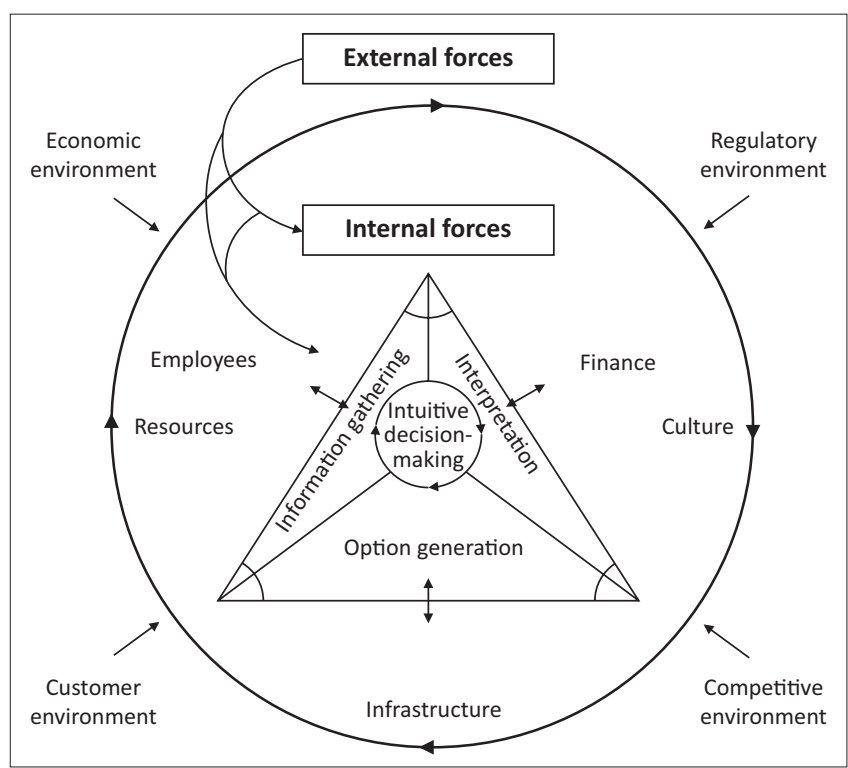

FIGURE 1: Integrated model of the strategic decision-making process in small and micro enterprises in South Africa. 
Each factor identified in the external environment, as found in the model but not limited to the model, can be analysed by individual small businesses or specific sectors in order to determine the specific forces and influences this environment can have on the business or sector. Therefore, the model can provide a guide to business practitioners and policymakers for identifying external forces relevant to each business or specific sector. Thus, more detailed and focused analysis of current and possible external factors will assist businesses in anticipating external environmental changes to which small and micro business are found to be subjugated, as depicted by the arrows in Figure 1.

Users of the model can benefit from identifying and understanding the internal forces that can affect decisionmaking or be affected by the decisions as indicated by the two-way arrows. The model can help identify the internal resource capital available to the firm that can be leveraged in order to achieve its objectives. The model helps the user identify certain internal resource capabilities, which will vary from one business to another, that form the basis of the small business's response to the external environmental pressures.

Therefore, the model can act as an archetype to decisionmakers in deciphering the internal resources unique to their business and how those resources can be effectively exploited.

In devising training and development programmes for small and micro enterprises, or business owners attempting to understand the process of decision formation, the model depicts the decision-making process as alternating and iterative in its mode, as seen by the circular effect of the arrows depicting the internal environment.

Consequently, in guiding decision-makers on strategic decision formulation, training programmes and literature must consider the non-sequential order of the decision formation process rather than impose a method that is irregular on the small and micro business owners. Also, the model can help users in understanding the simplicity of the phases and the overlapping nature of each aspect in the decision-making process. This will therefore provide a flexible framework that can be used as a benchmark in order to demonstrate a possible approach to decision-making that is not necessarily procedural.

Finally, the model demonstrates the significant dependency on intuitive tendencies to shape the decision-making process. Although business owners and policymakers may introduce the concept of analytical rationality to the decision-making process among small and micro business owners, the model can help the users to appreciate the important role that intuition performs in forging the overall direction of the business.

\section{Contribution of the study}

Understanding the process by which small and micro enterprises make strategic decisions possesses the proclivity for significant contribution to the small business sector in South Africa. The study offers both theoretical and practical sensitivities into the apparatuses used by small and micro decision-makers and policy-makers during their decision formation.

The first theoretical contribution addresses the gap in the literature regarding the mode of decision-making among small and micro businesses in South Africa. The study also offers a deeper notional understanding of the macro and micro situational variables affecting the decision-making capacity of the enterprises.

The second theoretical contribution addresses the intuitionrational decision-making continuum. The findings of the study challenge the notion of procedural rationality and its applicability to the strategic decision-making process in the context of small and micro enterprises in the services sector in South Africa. The findings showed that the preferential mode of decision-making was inclined towards intuitive tendencies on the intuition-rational decision-making continuum rather than analytical proficiencies.

The third theoretical contribution addresses the steps in the decision-making process. The study indicated that the phases of the strategic decision-making process were uncomplicated among the business owners.

The process constituted information gathering, interpretation and options for implementation. However, these phases in the process were non-sequential and allowed overlaps and interconnectivity in the phases of decision formation rather than a step-by-step approach to making decisions. Therefore, the theoretical implication is that decision strategies emerged in an iterative and informal style among the small and micro enterprises as opposed to a procedural rational style.

From a practical perspective, understanding the character of the strategic decision-making process contributes by aiding government agencies and policymakers in designing appropriate programmes for the development of small and micro enterprises. Developmental programmes should include specific training courses in strategic decision-making which unequivocally target the largest category of business, that is, small and micro enterprises. In other words, interventionists must copiously comprehend the existing decision processes and accept the uniqueness of the decisionmaking mode before designing a training programme on enhancing decision formation.

A second practical contribution of this study resides with the owners of these businesses. The owners are now challenged to reassess their decision-making process in order to identify areas of strengths and weaknesses in the manner of formulating strategic decisions in order to guide the owners towards improvement in sustainability and performance of the business. In so doing, the owners can 
better understand and develop each phase of the decisionmaking process in order to enhance its effectiveness.

\section{Future research}

In order to further enrich the insight and understanding of thestrategic decision-making process, a few recommendations are proposed for consideration:

- More research should be conducted about the strategic decision-making processes in different industries that can be utilised to compare and contrast understandings about the decision-making process in various contexts.

- Future research can focus on the informal sector which is a large segment of the small and micro business sector in order to determine the character and process of their strategic decision formation.

- Future studies can explore the competitiveness, growth and sustainability of strategic decision-making effectiveness on the businesses. Such a study may require a longitudinal, case study approach in order to completely assess the strategic decision-making process against measurable outcomes over a period of time.

- Future studies can examine the personal characteristics and cognitive biases of the owners in the decision-making process. Such a study should include an assessment of each owner's managerial experience, educational attainments and personality type in influencing the intuitive-rational decision-making continuum.

- Future studies can conduct similar research on medium and large organisations to determine the relative similarities of the decision-making processes between the various sizes of firms in the same industry and in different industries.

\section{Conclusion}

The significance of the small and micro enterprises has been acknowledged globally because of their role in economic development. In recognising the importance of this particular sector, noticeable attention is given by governments and academics to the factors affecting the growth and sustainability of these enterprises. Although a considerable amount of study examined the strategic decision-making (SDM) process among medium and small enterprises, there is a deficiency of literature pertaining to SDM process in the small and micro enterprises in the service sector in South Africa. Through the utilization of a qualitative exploratory approach, this study has rendered practical and theoretical contributions by examining this under-researched area of study. Due to the ungenerous number of literature pertaining to strategic decision-making in small and micro enterprises generally, and the small and micro enterprises in the services sector specifically, the study provides a consequential conception to the mode of the strategic decision-making process among this particular sector. The main results signify an orientation towards an intuitive mode of strategic decision-making among the business owners. The integrated theoretical model presented in the study is a further theoretical contribution aimed to intensify the understanding of the strategic decision-making process in small and micro enterprises.

\section{Acknowledgements Competing interests}

The authors declare that no competing interest exists.

\section{Authors' contributions}

All authors contributed equally to this work.

\section{Ethical consideration}

This article followed all ethical standards for research without direct contact with human or animal subjects.

\section{Funding information}

The research received no specific grant.

\section{Data availability statement}

New data has been created for this study.

\section{Disclaimer}

The views and opinions expressed in this article are those of the authors and do not necessarily reflect the official policy or position of any affiliated agency of the authors.

\section{References}

Asiamah, N., Mensah, H.K. \& Oteng-Abayie, E.F., 2017, ‘General, target, and accessible population: Demystifying the concepts for effective sampling', The Qualitative Report 22(6), 1607-1621.

Ayandibu, A.O. \& Houghton, J., 2017, 'The role of small and medium scale enterprise in local economic development (LED)', Journal of Business and Retail Management Research 11(2), 133-139.

Bushe, B., 2019, 'The causes and impact of business failure among small to micro and medium enterprises in South Africa', Africa's Public Service Delivery and Performance Review 7(1), 1-26. https://doi.org/10.4102/apsdpr.v7i1.210

Cant, M.C. \& Wiid, J.A., 2013, 'Establishing the challenges affecting South African SMEs', The International Business \& Economics Research Journal 12(6), 707-716. https://doi.org/10.19030/iber.v12i6.7869

Cant, M.C., Wiid, J.A. \& Kallier, S.M., 2015, 'Product strategy: Factors that influence product strategy decisions of SMEs in South Africa', Journal of Applied Business Research (JABR) 31(2), 621-630.https://doi.org/10.19030/jabr.v31i2.9158

Cheng, W., Kadir, K.A. \& Bohari, A.M., 2014, 'The strategic planning of SMEs in Malaysia: A view of external environmental scanning', International Journal of Business and Society 15(3), 437-446.

Cowling, M., Liu, W., Ledger, A. \& Zhang, N., 2015, 'What really happens to small and medium-sized enterprises in a global economic recession? UK evidence on sales and job dynamics', International Small Business Journal 33(5), 488-513. https:// doi.org/10.1177/0266242613512513

Efendioglu, A.M. \& Karabulut, T., 2010, 'Impact of strategic planning on financial performance of companies in Turkey', International Journal of Business and Management 5(4), 3-12. https://doi.org/10.5539/ijbm.v5n4p3

Eisenhardt, K.M. \& Zbaracki, M.J., 1992, 'Strategic decision making', Strategic Management Journal 13(S2), 17-37. https://doi.org/10.1002/smj.4250130904

Elbanna, S. \& Fadol, Y., 2016, 'The role of context in intuitive decision-making', Journal of Management \& Organization 22(5), 642-661. https://doi.org/10.1017/jmo. 2015.63

Etikan, I., Musa, S.A. \& Alkassim, R.S., 2016, 'Comparison of convenience sampling and purposive sampling', American Journal of Theoretical and Applied Statistics 5(1), 1-4. https://doi.org/10.11648/j.ajtas.20160501.11

Gao, Y. \& Hafsi, T., 2018, 'Does charitable giving substitute or complement firm differentiation strategy? Evidence from Chinese private SMEs', European Management Review 1, 1-14. https://doi.org/10.1111/emre.12180 
Groepe, F., 2015, 'The role of small business in the economy', in AHI conference on 'The role of business in local government and local economic development', South The role of bust ' African Reserve Bank, viewed 01 October 2018, from https://www.resbank.co.za/ 2015\%20.pdf.

Gronum, S., Verreynne, M. \& Kastelle, T., 2012, 'The role of networks in small and medium-sized enterprise innovation and firm performance', Journal of Small Business Management 50(2), 257-282. https://doi.org/10.1111/j.1540-627X. 2012.00353.x

Gupta, A., 2013, 'Environment \& PEST analysis: An approach to external business', International Journal of Modern Social Sciences 2(1), 34-43.

Haase, H. \& Franco, M., 2011, 'Information sources for environmental scanning: Do industry and firm size matter?', Management Decision 49(10), 1642-1657. https://doi.org/10.1108/00251741111183807

Hang, X. \& Wang, C., 2012, 'Strategic decision-making in small and medium-sized enterprises: Evidence from Australia', International Journal of Business Studies 20(1), 91-110.

Honig, B. \& Samuelsson, M., 2012, 'Planning and the entrepreneur: A longitudinal examination of nascent entrepreneurs in Sweden', Journal of Small Busines Management 50(3), 365-388. https://doi.org/10.1111/j.1540-627X.2012.00357.X

Huang, X., 2009, 'Strategic decision making in Chinese SMEs', Chinese Management Studies 3(2), 87-101. https://doi.org/10.1108/17506140910963602

Jocumsen, G., 2004, 'How do small business managers make strategic marketing decisions? A model of process', European Journal of Marketing 38(5/6), 659-674. https://doi.org/10.1108/03090560410529277

Kutllovci, E. \& Shala, V., 2013, 'The role of strategic management on small business growth in Kosova', International Journal of Business and Social Research 3(4), 87-92.

Lekhanya, L.M., 2015, 'Leadership and corporate governance of small and medium enterprises (SMES) in South Africa', Public Perceptions 12(3), 215-222. https:// doi.org/10.22495/cocv12i3c2p1

Liberman-Yaconi, L., Hooper, T. \& Hutchings, K., 2010, 'Toward a model of understanding strategic decision-making in micro-firms: Exploring the Australian information technology sector', Journal of Small Business Management 48(1), 70-95. https://doi.org/10.1111/j.1540-627X.2009.00287.x

Malewska, K., 2015, 'Intuition in decision making - Theoretical and empirical aspects', International Journal of Business and Economic Development 3(3), 97-105.

Marshall, B., Cardon, P., Poddar, A. \& Fontenot, R., 2013, 'Does sample size matter in qualitative research?: A review of qualitative interviews in IS research', Journal of Computer Information Systems 54(1), 11-22.https://doi.org/10.1080/08874417. 2013.11645667

Masutha, M. \& Rogerson, C.M., 2014, 'Small business incubators: An emerging phenomenon in South Africa's SMME economy', Urbanilzziv25, S47-S62. https:// doi.org/10.5379/urbani-izziv-en-2014-25-supplement-004
Mintzberg, H., Raisinghani, D. \& Theoret, A., 1976, 'The structure of "unstructured" decision processes', Administrative Science Quarterly 21(2), 246-275. https://doi. org/10.2307/2392045

Mitchelmore, S. \& Rowley, J., 2013, 'Growth and planning strategies within womenled SMEs', Management Decision 51(1), 83-96. https://doi.org/10.1108/ 00251741311291328

Olawale, F. \& Garwe, D., 2010, 'Obstacles to the growth of new SMEs in South Africa: A principal component analysis approach', African Journal of Business Management 4(5), 729-738.

Orser, B.J., Hogarth-Scott, S. \& Riding, A.L., 2000, 'Performance, firm size, and management problem solving', Journal of Small Business Management 38(4), $42-58$.

Pina, E.C.M., 2007, 'Entrepreneurship as decision making: rational, intuitive and improvisational approaches', Journal of Enterprising Culture, 15(1), 1-20.

Robinson, R.B. \& Pearce, J.A., 1984, 'Research thrusts in small firm strategic planning', The Academy of Management Review 9(1), 128-137. https://doi.org/10.5465/ amr.1984.4278109

Sandada, M., Pooe, D. \& Dhurup, M., 2014, 'Strategic planning and its relationship with business performance among small and medium enterprises in South Africa', The International Business \& Economics Research Journal 13(3), 659-669. https:// doi.org/10.19030/iber.v13i3.8602

Sandberg, W.R., Robinson, R. \& Pearce, J.A., 2001, 'One more time...should small companies attempt strategic planning?', Entrepreneurial Executive 6, 1-11.

South Africa NCR 2011, Literature review on small and medium enterprises' access to credit and support in South Africa, Government Printer, pp. 1-91, National Credit Regulator, Pretoria.

South Africa SONA, 2019, The President of the Republic of South Africa, Mr Cyril Ramaphosa presents the first State of the National Address (SoNA) of the 6th Parliament on 20 June 2019, viewed 19 October 2019, from https://www.gov.za/ sona2019.

Van Scheers, L. \& Makhitha, K.M., 2016, 'Are small and medium enterprises (SMEs) planning for strategic marketing in South Africa?', Foundations of Management 8(1), 243-250. https://doi.org/10.1515/fman-2016-0019

Verreynne, M., 2006, 'Strategy-making process and firm performance in small firms', Journal of Management \& Organization 12(3), 209-222. https://doi.org/10.1017/ S1833367200003965

Williams, R.I. Jr, Manley, S.C., Aaron, J.R. \& Daniel, F., 2018, 'The relationship between a comprehensive strategic approach and small business performance', Journal of Small Business Strategy 28(2), 33-48.

Zacca, R., Dayan, M. \& Elbanna, S., 2017, 'The influence of conflict and intuition on explorative new products and performance in SMEs', Journal of Small Business and Enterprise Development 24(4), 950-970. https://doi.org/10.1108/ JSBED-02-2017-0034 